\title{
Energy cost of the activities of grazing cows, effect of plot size
}

\author{
A. Brosh ${ }^{1,4}$, Z. Henkin ${ }^{1}$, E.D. Ungar ${ }^{2}$, A. Dolev ${ }^{3}$, A. Orlov ${ }^{1}$, \\ Y. Yehuda ${ }^{3}$, A. Shabtay ${ }^{1}$ and Y. Aharoni ${ }^{1}$ \\ ${ }^{1}$ Beef Cattle Section, ARO, Newe Yaar Center, Israel \\ ${ }^{2}$ Department of Natural Resources, ARO, Israel \\ ${ }^{3}$ MIGAL - Technological Center Israel, Newe-Ya'ar Research Center \\ P.O. Box 1021, Ramat Yishay, 30-095, Israel
}

\begin{abstract}
The energy expenditure and energy cost of activities of grazing beef cows were determined (by using the heart-rate method and GPS collars with motion sensors) on different size plots on Mediterranean foothill herbaceous rangeland, in three seasons. In winter plot size had no effect on the time spent on each activity or on the energy cost of these activities. In the summer, however, when the herbage was dry, cows on large plots grazed longer and expended more energy on grazing activity. It is suggested that on larger plots cows could select herbage of better quality than when grazing smaller plots.
\end{abstract}

KEY WORDS: grazing cattle, activity, energy cost, Global Positioning System, heart rate, plot size

\section{INTRODUCTION}

Time spent, distance travelled and energy cost of the activities of cows grazing on plots of 28 ha throughout the entire day were first measured by Brosh et al. (2006). They used the heart-rate method for measuring energy expenditure (EE) and Global Positioning System (GPS) collars, equipped with motion sensors. Plot size may affect animals' behaviour because in larger plots each individual cow has a larger area to explore for herbage selection, and this may affect its allocations of time, distance, and energy expenditure among its activities, and consequently may affect its total daily EE. The objective of the present study was to measure the energy costs of activities and the daily EE of cows grazed on large plots, for comparison with data previously obtained in smaller plots. 


\section{MATERIAL AND METHODS}

The experimental plots and treatment procedures are described in a companion paper in this journal issue (Henkin et al., 2007).

\section{Animals and measurements}

Mature, medium-frame-size cows aged about 7 year were used in the study. The cows were Simmental $\times$ Hereford crossbreds, with some blood from local eastern Mediterranean breeds. Daily energy expenditure (EE) measurements were conducted on 17 animals: 5 in late winter, 5 in early summer, and 7 in late summer, and the data obtained were compared with those obtained in a previous study (Brosh et al., 2006). The latter had used between 4 and 6 cows under the same low-stocking-rate treatment $(1.8 \mathrm{ha} / \mathrm{cow})$ during the same seasons and grazing on herbage of similar quality and biomass (Table 1 ). The mean body weight (BW) of the cows was $422 \pm 12$ in late winter, $477 \pm 22$ in early summer, and $477 \pm 25 \mathrm{~kg}$ in late summer.

Table 1. Standing biomass, chemical composition, ME content of the herbage samples in the trial seasons: in the two years studies on small plots (year 1) and large plots (year 2)

\begin{tabular}{|c|c|c|c|c|c|c|c|}
\hline \multirow{3}{*}{$\begin{array}{l}\text { Season } \\
\text { Plot size }\end{array}$} & & \multirow{2}{*}{\multicolumn{2}{|c|}{$\begin{array}{l}\text { Winter } \\
\text { late }\end{array}$}} & \multicolumn{4}{|c|}{ Summer } \\
\hline & & & & \multicolumn{2}{|c|}{ early } & \multicolumn{2}{|c|}{ late } \\
\hline & & large & small & large & small & large & small \\
\hline Biomass, & $\mathrm{kg}$ of $\mathrm{DM} / \mathrm{ha}$ & 1084 & 963 & 2415 & 2278 & 1104 & 1185 \\
\hline NDF & $\mathrm{g} / \mathrm{kg}$ of DM & 364 & 566 & 673 & 697 & 543 & 651 \\
\hline $\mathrm{CP}$ & $\mathrm{g} / \mathrm{kg}$ of DM & 195 & 170 & 54 & 46 & 46 & 41 \\
\hline ME & $\mathrm{MJ} / \mathrm{kg}$ of $\mathrm{DM}$ & 11.36 & 10.38 & 6.18 & 6.28 & 6.20 & 6.28 \\
\hline
\end{tabular}

EE was determined by multiplying heart rate, as measured throughout 4 days (once every one minute), by the $\mathrm{O}_{2}$ pulse $\left(\mathrm{O}_{2} /\right.$ beat), as measured over 10- to 15min intervals, according to Brosh et al. (2006).

The measurements of distance travelled, and the cows' activities are described in a companion paper in this journal issue (Henkin et al., 2007). Horizontal and vertical locomotion distances, and activities were determined and recorded over 5-min intervals.

\section{Model analyses of energy cost of activities}

A total of 11,976 records, taken from 17 cows over 5-min intervals throughout 4 days were collected. Each record included the following factors and continuous variables. Factors: cow identification (17 levels); reproductive state (3 levels: 
lactating, empty and pregnant); season (3 levels as described above); time of day (24 hourly levels); activity (4 levels: lying, standing, grazing and walking). Continuous variables: body condition score (BCS, scale 1-5), horizontal and vertical distances travelled (metres per 5-min), and EE $\left(\mathrm{kJ} \cdot \mathrm{kg} \mathrm{BW}^{-0.75} \cdot \mathrm{d}^{-1}\right)$. Although EE and activities were recorded over 5-min intervals, the costs of activities are presented as per-day values, i.e. the cost over $24 \mathrm{~h}$ (had the cows engaged in the activity for $24 \mathrm{~h}$ ). The presented locomotion costs correspond to $1 \mathrm{~m}$ of movement. Three models were used to relate sets of independent factors and variables to $\mathrm{EE}$, which was the dependent variable: 1. the stepwise model; 2. similar to model 1 , with the season and the season $\times$ time-of-day interaction excluded; and 3. only activity, i.e. season, time of day and BCS were not used in this model. All analyses were done with the Restricted Maximum Likelihood (REML) procedure, with fixed effects of the factors and variables in each model, and a random effect of cow.

\section{RESULTS}

Herbage standing biomass, chemical composition and calculated ME concentrations for each season are presented in Table 1; significant differences $(\mathrm{P}<0.001)$ were found among seasons but not between plot sizes.

The energy costs of activity, in excess of that used in the lying-down state, as estimated by the three models for the cows grazed on large plots, are presented in Table 2. The $\mathrm{R}^{2}$ values of all three models were high, and the estimates of the activity costs and of locomotion were highly significant $(\mathrm{P}<0.001)$ in all models. The estimated costs of being in the grazing state and of vertical positive locomotion were higher $(\mathrm{P}<0.05)$ according to model 3 than according to models 1 and 2.

Table 2. Model ${ }^{1}$ estimations, for large plots, of coefficients of energy expenditure (EE) of grazing cows in excess of that in the lying-down state (lying) attributed to their activities and distances of movement

\begin{tabular}{|c|c|c|c|c|c|c|c|c|c|c|c|c|}
\hline \multirow{2}{*}{ Model - } & \multicolumn{6}{|c|}{ Activity above lying down ${ }^{2}$} & \multicolumn{6}{|c|}{ Movement $^{3}$} \\
\hline & $\mathrm{R}^{2,4}$ & ST & WA & GR & SEM & $\mathrm{P}<$ & HOR & SEM & $\mathrm{P}<$ & VEP & SEM & $\mathrm{P}<$ \\
\hline 1 & 0.60 & 43.2 & 86.1 & 89.4 & 4.2 & 0.001 & 2.805 & 0.135 & 0.001 & 21.42 & 1.36 & 0.001 \\
\hline 2 & 0.58 & 42.7 & 84.5 & 90.8 & 4.3 & 0.001 & 2.798 & 0.138 & 0.001 & 22.22 & 1.39 & 0.001 \\
\hline 3 & 0.55 & 46.2 & 92.4 & 103.2 & 4.3 & 0.001 & 2.925 & 0.142 & 0.001 & 27.92 & 1.40 & 0.001 \\
\hline
\end{tabular}

${ }^{1}$ the models are described in Material and methods; ${ }^{2}$ activity states $\left(\mathrm{kJ}^{\mathrm{kgBW}} \mathrm{kg}^{-0.75} \cdot \mathrm{d}^{-1}\right)$ : ST- standing, WA- walking idle (without grazing), GR - grazing; ${ }^{3}$ movement $\left(\mathrm{J} \cdot \mathrm{kgBW}^{-0.75} \cdot \mathrm{d}^{-1}\right.$ for $\mathrm{m}$ locomotion): HOR - horizontal, VRP - vertical positive locomotion

${ }^{4} \mathrm{R}^{2}$ defines the fraction of total variance that was accounted for by the entire model 
Time and distance spent in each activity by the cows are presented and discussed in the companion paper in this journal issue (Henkin et al., 2007).

Daily energy costs (throughout the seasons) of specific activities of the cows grazing on large plots and small plots (Brosh et al., 2006) are presented in Table 3. The data were first summarized as the cost of being in each activity state and the sum of the horizontal and vertical locomotion costs. Then, the horizontal and vertical locomotion costs were allocated according to the distances travelled when cows grazed and walked. Thus the sums of the costs of grazing and of walking represent the entire costs of the respective activities, i.e. being in the activity state plus the cost of the locomotion during that activity.

Table 3. Sum of daily energy cost of each activity $\left(\mathrm{kJ} \cdot \mathrm{kg} \mathrm{BW}^{-0.75} \cdot \mathrm{d}^{-1}\right)$ in excess of that in the lying down position; calculated for the large and small plots according to the time spent on each activity and to locomotion distances; sum of daily costs of each activity in proportion to the sum of daily energy cost of all activities (sum EAC), total daily EE and sum EAC in proportion to total daily EE

\begin{tabular}{|c|c|c|c|c|c|c|}
\hline \multirow{3}{*}{$\frac{\text { Season }}{\text { Plot size }}$} & \multirow{2}{*}{\multicolumn{2}{|c|}{$\begin{array}{c}\text { Winter } \\
\text { late }\end{array}$}} & \multicolumn{4}{|c|}{ Summer } \\
\hline & & & \multicolumn{2}{|c|}{ early } & \multicolumn{2}{|c|}{ late } \\
\hline & large & small & large & small & large & small \\
\hline Standing state & 12.0 & 14.3 & 16.3 & 22.7 & 15.2 & 19.2 \\
\hline Grazing state & 43.6 & 47.0 & 31.0 & 22.8 & 27.7 & 22.1 \\
\hline Walking state & 0.71 & 0.79 & 1.46 & 1.45 & 3.84 & 1.01 \\
\hline Sum horizontal locomotion & 7.41 & 9.57 & 7.04 & 6.63 & 9.96 & 4.71 \\
\hline Sum vertical locomotion & 2.56 & 0.87 & 1.82 & 0.51 & 2.66 & 0.40 \\
\hline Grazing locomotion, horizontal + vertical & 8.91 & 8.59 & 6.86 & 3.75 & 5.81 & 3.13 \\
\hline Walking locomotion, horizontal + vertical & 1.06 & 1.85 & 2.00 & 3.38 & 6.81 & 1.98 \\
\hline Sum grazing cost & 52.5 & 55.6 & 37.9 & 26.5 & 33.5 & 25.2 \\
\hline Sum walking cost & 1.77 & 2.64 & 3.46 & 4.83 & 10.65 & 3.00 \\
\hline Sum EAC & 66.2 & 72.6 & 57.6 & 54.1 & 59.3 & 47.5 \\
\hline Sum of standing, $\%$ of sum EAC & 18.1 & 19.7 & 28.2 & 42.0 & 25.5 & 40.5 \\
\hline Sum of grazing, $\%$ of sum EAC & 79.3 & 76.6 & 65.8 & 49.0 & 56.5 & 53.2 \\
\hline Sum of walking, $\%$ of sum EAC & 2.7 & 3.6 & 6.0 & 8.9 & 18.0 & 6.3 \\
\hline Total daily EE & 1014 & 954 & 679 & 477 & 644 & 545 \\
\hline Sum EAC, $\%$ of total daily EE & 6.5 & 7.6 & 8.5 & 11.3 & 9.2 & 8.7 \\
\hline
\end{tabular}

The energy costs of being in grazing state in small plots, in late winter, early summer and late summer were found to be $46.2,62.2$, and $91.0\left(\mathrm{~kJ} \cdot \mathrm{kg} \mathrm{BW}^{-0.75} \cdot \mathrm{d}^{-1}\right)$ respectively, and that of horizontal locomotion $2.92\left(\mathrm{~J}^{\mathrm{kgBW}} \mathrm{kg}^{-0.75} \cdot \mathrm{m}^{-1}\right)$ (Brosh et al., 2006). Similar energy costs were found in the large plots (Table 2). However, the estimated costs of being in the walking state and of vertical locomotion in large plots were greater $(\mathrm{P}<0.05)$ than those calculated for the small plots. In the present study, on the large plots the estimated cost of vertical locomotion was 8.4 times that of horizontal locomotion, which is very close to that reported by Lachica et al. (1997), which was 9 times that of horizontal locomotion. Investigation of the 
cows' behaviour showed that those in large plots spent more time walking, and travelled longer distances without stopping than those in small plots, therefore the estimated energy cost of being in walking idle state was greater in large plots than in small plots, and the estimated cost of vertical locomotion is more realistic than the previous estimate for small plots. It is suggested that there is a time delay between the beginning of an activity (which causes a measurable increase in HR and EE) and the time at which it is fully expressed in HR level, and, consequently in the calculated EE. In addition, we consider that vertical distance was measured more accurately when the locomotion distance was longer.

Total daily energy costs of activities $\left(\mathrm{kJ} \cdot \mathrm{kgBW}^{-0.75} \cdot \mathrm{d}^{-1}\right)$ of the comparable seasons on large vs small plots are presented in Table 3. The data were calculated by multiplying the average cost of being in each activity state by the time spent on this activity, plus the locomotion cost of the distance travelled. Consequently, the data could not be analysed statistically, but the components of the energy cost, i.e. the cost of being in an activity state and of locomotion, time spent and distances travelled for each activity were analysed.

The total costs of grazing for cows on large plots were similar to those on small plot when cows grazed on high-quality green, lush herbage in late winter, but were higher by 43 and $33 \%$ on large than on small plots in early and late summer, respectively. We consider that this difference was the result of greater selectivity for higher quality herbage in large than in small plots.

The total costs of walking for cows on large plots were 67 and $71 \%$ of those on small plot in late winter and early summer, respectively, but was 3.55 times as great in late summer; the difference in the time spent walking idle (2.9 times as long on the large than on the small plot in late summer; Henkin et al., 2007) accounts for most of the difference.

The sum of all activity energy costs (Sum EAC) was most affected by the grazing cost and least by the walking-idle cost. The daily cost of vertical locomotion, as a proportion of Sum EAC, was very low, so that the effect of errors in estimating its contribution to Sum EAC in the small plot is negligible. When cows grazed on high-quality herbage (late winter) Sum EAC was maximal, and was similar on large and small plots. It was also similar in large and small plots in early summer, in spite of the longer grazing time and greater grazing cost in large than in small plots; this was because the standing cost was smaller in large than in small plots. The greatest difference between Sum EAC in large and that in small plot $(25 \%$ greater in large plots) was measured in late summer, because of the longer grazing periods and consequently greater energy costs of grazing and walking in large than in small plots.

Increases in the total daily $\mathrm{EE}$ of productive ruminants mainly result from increases in metabolizable energy intake (Brosh, 2007). Similarly to the previous findings for the small plot (Brosh et al., 2006), in the present study the total daily 
EE increased as Sum EAC increased, but Sum EAC as a fraction of total daily EE decreased as Sum EAC and total daily EE increased. As the Sum EAC was a relatively small proportion of the total daily EE (Table 3), we suggest that for the situation presented in this paper, the greater total daily EE in the large than in the small plots in the summer, indicates that the cows grazing on larger plots have the opportunity to explore a larger area and to find better-quality herbage. Consequently, they have better energy balance than cows grazing on small plots.

\section{CONCLUSIONS}

Cows manage their grazing behaviour according their capability to improve their energy balance. Consequently, the time and energy spent in grazing are positively related to herbage quality and availability. When cows grazed on dry herbage that contained sufficient biomass, larger plots offered them a wider variety of herbage for selection; consequently they grazed for longer periods and expended more energy in the process, but probably consumed more and higher quality herbage than in small plots, which was expressed in the greater total daily energy expenditure in large than in small plot in early and late summer.

\section{REFERENCES}

Brosh A., 2007. Heart rate measurements as an index of energy expenditure and energy balance in ruminants: A review. J. Anim. Sci. 85, 1213-1227

Brosh A., Henkin Z., Ungar E.D., Dolev A., Orlov A., Yehuda Y., Aharoni Y., 2006. Energy cost of cows' grazing activity: the use of heart rate GPS methods for direct field estimation. J. Anim. Sci. 84, 1951-1967

Henkin Z., Brosh A., Ungar E.D., Dolev A., Yehuda Y., Aharoni Y., 2007. The spatial distribution and activity of cattle in response to plot size. J. Anim. Feed Sci. 16, Suppl. 2, 399-404

Lachica M., Prieto C., Aguilera J.F., 1997. The energy cost of walking on the level and on negative and positive slopes in the Granadina goat (Capra hircus). Brit. J. Nutr. 77, 73-81 